\title{
Di-tungsten Bis-carbene Complexes Linked by Condensed Heteroaromatic Spacers
}

Simon Lotz ${ }^{\mathrm{a}}$, Marilé Landman ${ }^{\mathrm{a}}$, Helmar Görls ${ }^{\mathrm{b}}$, Chantelle Crause ${ }^{\mathrm{a}}$, Hubert Nienaber ${ }^{\mathrm{a}}$, and Andrew Olivier ${ }^{\mathrm{a}}$

${ }^{a}$ Department of Chemistry, University of Pretoria, Pretoria 0002, South Africa

${ }^{\mathrm{b}}$ Friedrich-Schiller-Universität, Institut für Anorganische und Analytische Chemie,

Lessingstraße 8, Jena 07743, Germany

Reprint requests to Dr. Simon Lotz. Fax: Int+27 12362 5297. E-mail: simon.lotz@up.ac.za

Z. Naturforsch. 2007, 62b, 419-426; received December 19, 2006

Dedicated to Prof. Helgard G. Raubenheimer on the occasion of his $65^{\text {th }}$ birthday

The 2,7-dilithiated substrates of 3,6-dimethylthieno[3,2-b] thiophene, $N, N^{\prime}$-dimethylpyrrolo[3,2$b]$ pyrrole and $N$-methylthieno[3,2-b]pyrrole were reacted with $\mathrm{W}(\mathrm{CO})_{6}$ to give, after subsequent alkylation with $\mathrm{Et}_{3} \mathrm{OBF}_{4}$, the ditungsten biscarbene complexes $\left[(\mathrm{CO})_{5} \mathrm{~W}\{\mathrm{C}(\mathrm{OEt}) \mathrm{XXC}(\mathrm{OEt})\}\right.$ $\left.\mathrm{W}(\mathrm{CO})_{5}\right](\mathrm{XX}=$ condensed heteroaromatic spacers $)$. Sites of attack during the dilithiation of the condensed rings were studied and compared, and the yields of the desired ditungsten biscarbene complexes optimized by changing the reaction conditions according to the role of the heteroatoms in the rings. The crystallographic data of the three ditungsten biscarbene complexes are reported and their structural features compared. The methyl substituents on the condensed heteroaromatic rings play an important role in determining the molecular configurations.

Key words: Dinuclear Carbene Complexes, Condensed Heterocycles, Thiophene, Pyrrole, Tungsten

\section{Introduction}

Fused heteroaromatic moieties functioning as bridging spacers in transition metal complexes have not yet been fully exploited and examples are limited to mostly main group metal compounds. Even though the coordination chemistry of thiophene and N-substituted pyrrole with transition metals has been studied extensively, this is not true for condensed heterocycles of thiophene and pyrrole $[1,2]$. The exceptional properties of condensed thiophene and pyrrole rings are finding many applications in organic synthesis and material science. Research in these areas has mainly been focused on the preparation of potential pharmacologically important compounds and polymeric materials with conducting properties $[3,4]$. Incorporating fused heteroaromatic substrates as linking units between transition metals is an attractive approach to study photoelectronic, charge transfer and metal-metal communication processes $[5,6]$. Furthermore, transition metal fragments acting as templates towards heterocyclic ligands can also play an important role in regio- and stereoselective syntheses in organic chemistry and thereby greatly advance heteroaromatic ring modifications [7-9].

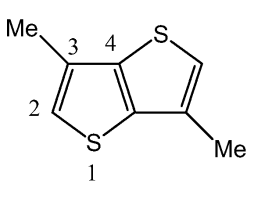

L1

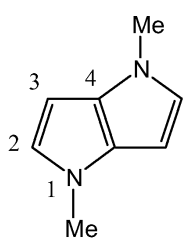

L2

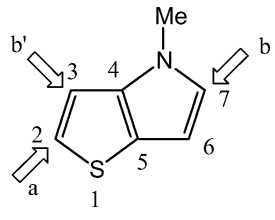

L3
Fig. 1. Atom numbering used for 3,6-dimethylthieno[3,2- $b]$ thiophene (L1), $N, N^{\prime}$-dimethylpyrrolo[3,2-b]pyrrole (L2) and $N$-methylthieno[3,2- $b]$ pyrrole $(\mathbf{L} \mathbf{3})$ and the sites of deprotonation of $\mathbf{L 3}$.

Since the properties of thieno[3,2- $b]$ thiophene derivatives as bridging linkers in transition metal carbene complexes have been explored in our laboratories $[10,11]$, a study of the analogous $\mathrm{N}$-substituted pyrrolo[3,2- $b$ ]pyrrole and the mixed heteroaromatic complexes, thieno[3,2- $b]$ pyrrole, was undertaken. The transfer of electron density of these electron excessive substrates to the very electrophilic carbene carbon atom in Fischer carbene complexes will aid in the stabilization of such multinuclear multicarbene functionalities.

The isomer of the condensed rings of thienopyrrole (L3) shown in Fig. 1, represents the most stable iso- 
mer of this type of compound [12]. When two fivemembered rings of thiophene and pyrrole are fused in this manner, the two rings display $\pi$ conjugation from positions 2 to 7 and hence could support charge transport over the whole molecule. They can act as excellent links between carbene ligands and hence create a pathway for metal-metal communication. The atom numbering shown in Fig. 1 is unconventional, but represents the labels used in this study for the reported crystal structures. The biscarbene complexes of tungsten were prepared with bridging 3,6-dimethylthieno[3,2$b]$ thiophene, $N, N^{\prime}$-dimethylpyrrolo[3,2-b]pyrrole and $N$-methylthieno[3,2- $b]$ pyrrole units and their structural features were investigated and compared in the solid state. This work is an extension of our previously published work dealing with dinuclear biscarbene complexes with bridging thiophene and furan spacers $[9,13]$.

\section{Results and Discussion}

Since no practical short-step syntheses for thieno$[3,2-b]$ thiophene, pyrrolo[3,2- $b]$ pyrrole or thieno[3,2$b$ ]pyrrole were available, several of the steps required to construct a second, fused pyrrole ring to the pyrrole or thiophene substrate, had to be revised to obtain higher yields of the desired compounds. The most general method for the synthesis of pyrrole-condensed heterocycles involves an alkyl azido-acrylate as key intermediate which undergoes facile thermal cyclization to yield the corresponding carboxy derivatives. The Fischer method for carbene synthesis is dependent on deprotonation steps of the substrates and it was therefore required to block active sites, $e . g$. by alkylating the $\mathrm{N}-\mathrm{H}$ bond in pyrrole and blocking the $\beta$ position in thieno[3,2-b]thiophene.

\section{Synthesis of condensed heteroaromatic precursors}

Choi and co-workers reported a one-pot synthesis of 3,6-dimethylthieno[3,2- $b$ ]thiophene [14]. The synthesis was based on the discovery made by Teste and Lozac'h that the reaction of 2,5-dimethyl-3hexyne-2,5-diol with elemental sulfur afforded 3,6dimethylthieno[3,2-b]thiophene (L1) [15]. To improve the low yield, Choi re-examined this reaction and varied the reaction conditions which were used to obtain L1.

The syntheses of $\mathbf{L 2}$ and $\mathbf{L 3}$ were based on the method of Hemetsberger and Knittel [16]. The yields over 5 steps were $20-25 \%$ and the route employed

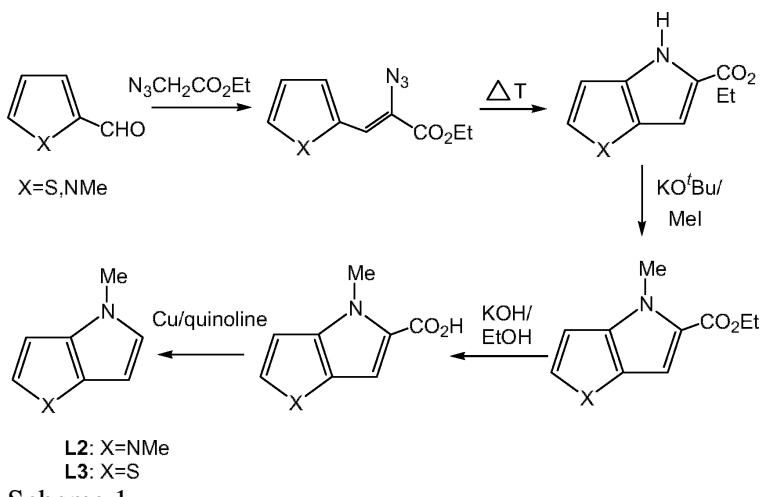

Scheme 1 .

for the synthesis is shown in Scheme 1. The first step involves the condensation of thiophene or $N$ methylpyrrole carboxaldehyde with ethyl azidoacetate to form the substituted vinyl azide. Thermolysis at $130{ }^{\circ} \mathrm{C}$ afforded the condensed pyrroles. To avoid $\mathrm{N}-\mathrm{H}$ deprotonation during metalation, it was necessary to prepare the $N$-methyl derivatives of $\mathbf{L} 2$ and $\mathbf{L 3}$. The $\mathrm{N}$ alkylation could be carried out either directly from the $4 \mathrm{H}$-pyrolyl- or $4 \mathrm{H}$-thienyl[3,2- $b]$ pyrrole, or as the last step of the procedure and was accomplished by deprotonation with potassium tert-butoxide and subsequent alkylation with methyl iodide. The last two steps of the synthesis involved basic hydrolysis of the ester functionality followed by copper catalyzed decarboxylation to afford $\mathbf{L 2}$ and $\mathbf{L 3}$, respectively.

\section{Synthesis of complexes}

The classical Fischer method forms the basis of the synthesis of the carbene ligands in $\mathbf{1}, \mathbf{2}$ and $\mathbf{3}$. Monometalation studies of heterocyclic systems have provided a general rule of oxygen $>$ sulfur $>$ nitrogen in increasing order of reactivity [17]. This rule prevails for $\mathrm{N}$-substituted nitrogen compounds, but not necessarily $\mathrm{N}-\mathrm{H}$ compounds. Two equivalents of butyl lithium, $\mathrm{W}(\mathrm{CO})_{6}$ and alkylating agent were used with one equivalent of the heterocycle. Monocarbene complexes are always formed in these reactions as a result of incomplete dilithiation. For $\mathbf{L 1}-\mathbf{L} 3$ the monolithiated species gave the corresponding monocarbene complexes, [W(CO) ${ }_{5}\{\mathrm{C}(\mathrm{OEt})$ heterocycle $\left.\}\right]$, but these compounds were not isolated and did not form part of this study.

It was however unclear how successful double lithiation of $\mathbf{L 1}-\mathbf{L 3}$ could be performed. Like sulfur, nitrogen also exhibits an ortho directing effect which would lead to the formation of the 2,7-dilithio deriva- 


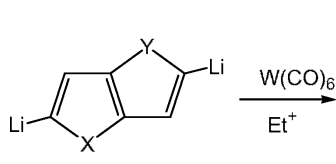

Scheme 2

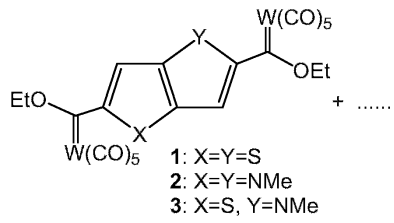

tive of $\mathbf{L 2}$. Whereas lithiation $\alpha$ to sulfur is favoured and occurs at low temperatures in THF, more stringent conditions are needed to deprotonate the position $\alpha$ to nitrogen in a pyrrole moiety. Double lithiation of thieno[3,2- $b]$ thiophene was improved once the 3 -positions on the thiophene rings were blocked. Although not the method of choice for this study, both protons in $\mathbf{L} \mathbf{1}$ could be removed in THF at low temperatures. This becomes more difficult for the deprotonation of $\mathbf{L 2}$, hence hexane is the solvent of choice to access higher temperatures, and TMEDA is employed as co-catalyst for the preparation of 2 .

It was found that the desired 2,7-dilithio derivative of $\mathbf{L 3}$ was not formed exclusively, but a 2,3-dilithiated thiophene could also be produced leaving the pyrrole ring unaffected, and consequently leading to a chelating cis biscarbene complex of tungsten. It can thus be concluded that a proton adjacent to the sulfur atom in thiophene will be removed preferentially during the first lithiation (a), but during the second lithiation, the $\beta$ position of the thiophene ring ( $\left.b^{\prime}\right)$ becomes a competitive site for lithiation with the position $\alpha$ to the nitrogen atom on the pyrrole ring (b). It was noted before that dilithiation of thieno[3,2- $b]$ thiophene gives a mixture of mono- and dilithiated species [10]. The ditungsten biscarbene complexes $\mathbf{1}, \mathbf{2}$ and $\mathbf{3}$ were prepared according to Scheme 2 and are of reasonable stability in solution under inert atmosphere. These complexes are oxidized with time at one of the metal centres to give $\left[\mathrm{W}(\mathrm{CO})_{5}\{\mathrm{C}(\mathrm{OEt}) \mathrm{XXC}(\mathrm{O}) \mathrm{OEt}\}\right]$ and other oxidation products [18]. In the solid state the biscarbene complexes can be stored indefinitely under inert atmosphere.

Three procedures were used in the synthesis of $\mathbf{3}$ and represent slight modifications of the general method. The first and general procedure to carbene-complex formation was based on the generation of a dilithiated nucleophile with $n$-BuLi/TMEDA in hexane [19]. The second method was tried to improve the yield of $\mathbf{3}$ and decrease the amount of monocarbene complex formation. This route comprised an adapted method of Aoki involving a stepwise lithiation approach [20]. $N$ Methylthieno[3,2- $b]$ pyrrole was mono-lithiated with
$n$-BuLi in THF at $0{ }^{\circ} \mathrm{C}$ and treated with $\mathrm{W}(\mathrm{CO})_{6}$ to form the metal acylate. Under these conditions the first proton is removed $\alpha$ to the sulfur atom in the thiophene ring. A second proton was abstracted by LDA at low temperature and the resulting dianion was reacted with a second equivalent of $\mathrm{W}(\mathrm{CO})_{6}$ followed by alkylation with triethyloxonium tetrafluoroborate. Again it was found that metalation $\beta$ to sulfur was competitive, but the overall yields of the biscarbene complexes were improved, while very little of the monocarbene complex was formed. Finally, and parallel with the first approach, the dilithiated ligand $\mathbf{L} \mathbf{3}$ was used as starting material. In contrast, only one equivalent of $\mathrm{W}(\mathrm{CO})_{6}$ was added and the resulting metal acylate was washed with several portions of hexane to remove unreacted starting materials. The residue was redissolved in THF and reacted with a second equivalent of the tungsten hexacarbonyl, followed by alkylation. This methodology improved the yield of the desired ditungsten biscarbene complex $\mathbf{3}$.

\section{Characterization of ligands and complexes}

Complexes 1-3 were characterized using infrared and ${ }^{1} \mathrm{H}$ NMR spectroscopy as well as mass spectrometry. Suitable crystals of $\mathbf{1 , 2}$ and $\mathbf{3}$ were obtained from dichloromethane/hexane solutions for X-ray diffraction studies. No molecular ion peak, $\mathrm{M}^{+}$, was observed in the mass spectrum of $\mathbf{3}$. The infrared frequencies and patterns observed in the carbonyl region confirm the presence of the $\mathrm{W}(\mathrm{CO})_{5}$ fragment for all the complexes. The coordination of the tungsten fragment via a carbene carbon atom has a significant effect on the electronic environment of the remaining ring protons of the hetero-rings and is reflected in the downfield chemical shift values recorded in the ${ }^{1} \mathrm{H}$ NMR spectra of the heterocycles as spacers in the complexes $(\mathbf{1}-\mathbf{3})$ compared to the uncoordinated heterocycles $(\mathbf{L 1}-\mathbf{L 3})$. Interestingly, the chemical shift values of the methylene protons of the carbene ethoxy groups in $\mathbf{3}$ attached to the thiophene ring is the same as in $\mathbf{1}$, and the corresponding resonances of the carbene attached to pyrrole are again the same as in $\mathbf{2}$. Thus, even though there is a flow of electron density from the hetero-ring to the carbene carbon atom, there is little evidence of electron delocalization across the two condensed rings or a flow of charge from one side of the spacer to the other.

\section{Description of crystal structures}

Single crystal X-ray diffraction studies confirmed the molecular structures of 1, 2 and 3. Selected bond 
Table 1. Selected bond lengths ( $\AA$ ), angles (deg), and dihedral angles (deg) for 1, 2 and 3 with estimated standard deviations in parentheses.

\begin{tabular}{|c|c|c|c|}
\hline Complex & $\begin{array}{l}1 \\
X=Y=S\end{array}$ & $\begin{array}{l}\mathbf{2} \\
\mathrm{X}=\mathrm{Y}=\mathrm{NMe}\end{array}$ & $\begin{array}{l}\mathbf{3} \\
\mathrm{X}=\mathrm{S}, \mathrm{Y}=\mathrm{NMe}\end{array}$ \\
\hline \multicolumn{4}{|l|}{ Distances } \\
\hline W-C1(carbene) & $2.221(8)$ & $2.238(4)$ & $2.212(6)$ \\
\hline W-CO (trans) & $2.028(8)$ & $2.038(5)$ & $2.029(7)$ \\
\hline $\mathrm{W}-\mathrm{CO}(\mathrm{cis})_{\mathrm{av}}$ & $2.05(1)$ & $2.056(5)$ & $2.040(7)$ \\
\hline $\mathrm{C} 1-\mathrm{C} 2$ & $1.46(1)$ & $1.453(6)$ & $1.466(8)$ \\
\hline $\mathrm{C} 2-\mathrm{C} 3$ & $1.40(1)$ & $1.402(6)$ & $1.350(11)$ \\
\hline C3-C4 & $1.427(9)$ & $1.408(5)$ & $1.287(12)$ \\
\hline${ }^{\mathrm{a}} \mathrm{C} 4-\mathrm{C} 4 \# / 5$ & $1.39(2)$ & $1.396(8)$ & $1.39(2)$ \\
\hline $\mathrm{C} 2-\mathrm{X}$ & $1.761(7)$ & $1.422(5)$ & $1.961(8)$ \\
\hline C2\#5-Y & & & $1.267(11)$ \\
\hline C4\#/5-X & $1.728(7)$ & $1.364(5)$ & $2.039(12)$ \\
\hline $\mathrm{C} 4-\mathrm{Y}$ & & & $1.392(13)$ \\
\hline \multicolumn{4}{|l|}{ Angles } \\
\hline $\mathrm{W}-\mathrm{C} 1-\mathrm{O}$ & $128.2(5)$ & $128.0(3)$ & $128.5(4)$ \\
\hline $\mathrm{W}-\mathrm{C} 1-\mathrm{C} 2$ & $125.7(5)$ & $123.9(3)$ & $123.4(5)$ \\
\hline $\mathrm{O}-\mathrm{C} 1-\mathrm{C} 2$ & $105.9(6)$ & $108.0(3)$ & $107.9(5)$ \\
\hline $\mathrm{C} 2 \# 5-\mathrm{X}-\mathrm{C} 4$ & $90.9(3)$ & 107.1(3) & $87.2(5)$ \\
\hline C2-Y-C4\#5 & & & $92.0(12)$ \\
\hline $\mathrm{X}-\mathrm{C} 2 \# 5-\mathrm{C} 3 \# 5$ & $113.2(5)$ & 108.6(3) & $121.6(5)$ \\
\hline $\mathrm{Y}-\mathrm{C} 2-\mathrm{C} 3$ & & & $97.9(7)$ \\
\hline C2-C3-C4 & 109.4(6) & 107.1(3) & $123.5(10)$ \\
\hline C3-C4-C\#4/5 & $115.3(8)$ & $108.2(3)$ & $96.0(10)$ \\
\hline C4-C4\#/5-X & $111.3(7)$ & $109.7(3)$ & $132.4(9)$ \\
\hline $\mathrm{C} 4 \# 5-\mathrm{C} 4 \mathrm{~A}-\mathrm{Y}$ & & & $109.4(11)$ \\
\hline \multicolumn{4}{|l|}{ Dihedral Angles } \\
\hline $\mathrm{W}-\mathrm{C} 1-\mathrm{C} 2-\mathrm{C} 3$ & $152.0(5)$ & $19.9(3)$ & $-18.1(4)$ \\
\hline $\mathrm{X}-\mathrm{C} 4 \# / 5-\mathrm{C} 4-\mathrm{Y}$ & 180 & 180 & 180 \\
\hline $\mathrm{O} 1-\mathrm{C} 1-\mathrm{C} 2-\mathrm{X}$ & $159.5(7)$ & $16.5(3)$ & $14.6(4)$ \\
\hline $\mathrm{O} 1-\mathrm{C} 8-\mathrm{C} 7-\mathrm{Y}$ & & & $-11.2(6)$ \\
\hline $\mathrm{C}-\mathrm{W}-\mathrm{C} 1-\mathrm{C} 2$ & $-38.8(6)$ & $-38.9(3)$ & $-41.5(3)$ \\
\hline
\end{tabular}

${ }^{\mathrm{a}}$ Symmetry transformations used for $\mathbf{1 , 2}$ and $\mathbf{3}$ to generate equivalent atoms are \#1: $-x,-y,-z$.

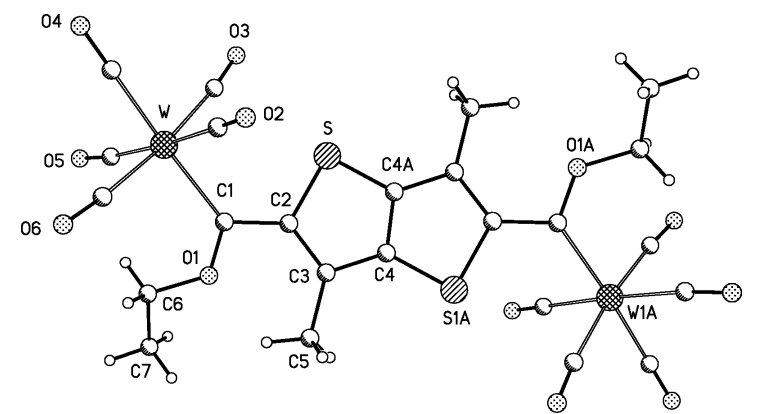

Fig. 2. Ball-and-stick representation of the molecular structure of 1 .

lengths and angles are given in Table 1, and Figs. 2, 3 and 4 represent ball-and-stick plots of the structures. The six ligands, five carbonyl groups and one carbene, are arranged octahedrally around each metal centre. Unlike for carbene complexes with bridging thiophene or furan units, the plane describing the hetero-

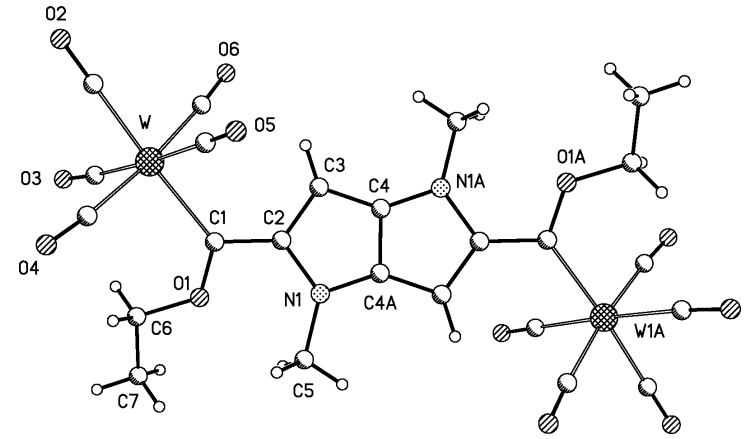

Fig. 3. Ball-and-stick representation of the molecular structure of 2 .

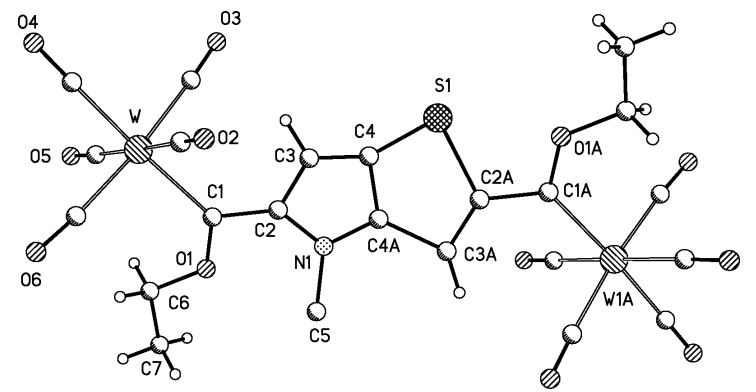

Fig. 4. Ball-and-stick representation of the molecular structure of 3

cycles and the plane of the carbene unit do not coincide with each other. In complexes $\mathbf{1}-\mathbf{3}$ these planes are displaced by $15-20^{\circ}$. Also, the carbene ligand deviates from the midpoint $\left(45^{\circ}\right.$, staggered position) between two perpendicular planes described by the tungsten carbonyl groups. This is ascribed to the bulkiness of the spacer and in particular to the methyl substituents attached to the rings in $\mathbf{1 - 3}$. Taking into consideration only electronic and packing effects, based on the many structures of carbene complexes with heterocyclic substituents studied in our laboratories, the heteroatom is preferentially found in a position on the same side as the ethoxy substituent and on the opposite side of the $\mathrm{W}(\mathrm{CO})_{5}$ fragment with respect to the $\mathrm{C}$ (carbene) $-\mathrm{C}$ (heterocycle) bond $[11,13]$. This we ascribe to the formation of a six-membered ring that includes the $\mathrm{Li}^{+}$, the heteroatom of the heterocycle and the oxygen atom of the intermediate metal acylate [21]. In addition, when carbene structures with heteroarene rings and their substituents are examined, there is more free space available around the ethoxy substituent compared with the bulkier $\mathrm{W}(\mathrm{CO})_{5}$ fragment. In 1-3 the methyl substituents determine the relative positioning of the ethoxy substituent and the $\mathrm{W}(\mathrm{CO})_{5}$ fragment around the carbene carbon atom. 
With the methyl groups in the $\mathrm{C} 3$ positions of the thiophene ring in $\mathbf{1}$, the thiophene sulfur atom is now in the unusual position on the opposite side of the ethoxy group. The shortest non-bonding (Et)O $\cdots \mathrm{H}(\mathrm{Me})$ distance is 2.10(1) $\AA$ which falls in the range associated with some hydrogen-oxygen interaction. For the methyl substituent on the nitrogen atom of the pyrrole rings in $\mathbf{2}$ and $\mathbf{3}$, the isomeric forms with the nitrogen atom on the same side as the ethoxy substituent of the $\mathrm{C}$ (carbene) $-\mathrm{C}$ (pyrrole) bonds are found. The shortest non-bonding $(\mathrm{Et}) \mathrm{O} \cdots \mathrm{N}(\mathrm{MeN})$ distance in $\mathbf{2}$ is 2.391(8) $\AA$, and in 3 2.768(4) $\AA$, indicating some hydrogen bonding. The bond lengths and angles do not differ significantly between the three structures, but one must take into account the differences of inter-ring angles at the heteroatoms in the thiophene and pyrrole rings. The carbene carbon atoms exhibit $s p^{2}$ character with angles distorted from ideal values as is expected for alkoxy carbene complexes. Because the metal fragment takes up more space, the angles on this side of the carbene carbon atom and its substituents are greater than $120^{\circ}$ [22].

The shortest $\mathrm{C}-\mathrm{C}$ bond lengths of the heterocyclic rings of the spacers in all the complexes are at the point where the rings are fused which supports ${ }^{1} \mathrm{H}$ NMR data suggesting very little electron delocalization over the rings. The $\mathrm{W}-\mathrm{C}$ (carbene) distances are the same, but comparison with $\mathbf{3}$ is complicated because of the large margin of error in the measurements.

\section{Experimental Section}

\section{General procedures}

All manipulations involving organometallic compounds made use of Schlenk techniques, and operations were carried out under inert atmosphere. Hexane, THF and dichloromethane were dried and deoxygenated by distillation prior to being used. Commercial thiophene was purified [23] and triethyloxonium tetrafluoroborate prepared according to reported procedures [24]. TMEDA was distilled before use. The reagents $\mathrm{W}(\mathrm{CO})_{6}$ and butyl lithium $\left(1.6 \mathrm{mmol} \mathrm{mL}^{-1}\right.$ solution in hexane) and all other commercial agents were used as purchased. Column chromatography, using silica gel $60(0.0063-0.200 \mathrm{~mm})$ as the stationary phase, was employed for all separations and purifications. Circulating cold water through the column jackets served to cool the columns. NMR spectra were recorded on a Bruker ARX-300 spectrometer and mass spectra on a Finnigan Mat 8200 instrument at $c a .70 \mathrm{eV}$ using the electron impact method. The ${ }^{1} \mathrm{H}$ NMR spectra were recorded at $300.135 \mathrm{MHz}$ and the signal of the deuterated solvent was used as reference $\left({ }^{1} \mathrm{H}\right.$ in $\left.\mathrm{CDCl}_{3}: 7.24 \mathrm{ppm}\right)$. IR spectra were recorded on a Perkin-Elmer Spectrum RXI FT-IR spectrophotometer using either dichloromethane or hexane as solvent. Only the vibration bands in the carbonyl stretching region ( $c a$. $1500-$ $2200 \mathrm{~cm}^{-1}$ ) are reported.

3,6-Dimethylthieno[3,2-b]thiophene (L1): The ligand was prepared by the method of Choi and was used in our laboratories earlier [14]. $-{ }^{1} \mathrm{H} \mathrm{NMR}\left(\mathrm{CDCl}_{3}\right): \delta=2.33$ (s, $\left.6 \mathrm{H}, \mathrm{CH}_{3}\right), 6.92$ (s, 2H, H2).

$N, N^{\prime}$-Dimethylpyrrolo[3,2-b]pyrrole (L2): The synthesis of $\mathbf{L} 2$ was adapted from literature and modified in our laboratories [25].

Condensation: $\mathrm{BrCH}_{2} \mathrm{COOEt}(83.5 \mathrm{~g}, 0.5 \mathrm{~mol})$, in $30 \mathrm{~mL}$ of $\mathrm{EtOH}$, and $\mathrm{NaN}_{3}(35.75 \mathrm{~g}, 0.55 \mathrm{~mol})$, in $90 \mathrm{~mL}$ of $\mathrm{H}_{2} \mathrm{O}$, were added together and heated under reflux for $4 \mathrm{~h}$. A steam distillation was carried out (to get rid of salts) and the organic layer was washed twice with water and dried over anhydrous $\mathrm{Na}_{2} \mathrm{SO}_{4}$. After this, a vacuum distillation was carried out with a water pump vacuum and the fraction between $62{ }^{\circ} \mathrm{C}$ and $65^{\circ} \mathrm{C}$ was isolated.

To a solution of sodium $(2.76 \mathrm{~g}, 120 \mathrm{mmol})$ in $55 \mathrm{~mL}$ of ethanol was added, under vigorous stirring at $5-10{ }^{\circ} \mathrm{C}$, a mixture of $\mathrm{N}_{3}-\mathrm{CH}_{2} \mathrm{COOEt}(15.48 \mathrm{~g}, 120 \mathrm{mmol})$ and $\mathrm{N}$ methylpyrrole aldehyde $(4.365 \mathrm{~g}, 40 \mathrm{mmol})$ over a period of 30 min. After the evolution of $\mathrm{N}_{2}$ had subsided (30$60 \mathrm{~min}$ ), half of the solution was distilled at a maximum temperature of $30{ }^{\circ} \mathrm{C}$. The brown solution was treated with solid $\mathrm{NH}_{4} \mathrm{Cl}(6.40 \mathrm{~g}, 120 \mathrm{mmol})$ and $500 \mathrm{~mL}$ of ice water. After this the solution was extracted 3 times with diethyl ether, filtered, washed with water until it was neutral, and then dried over $\mathrm{Na}_{2} \mathrm{SO}_{4}$. The solvent was distilled off and the brown residue dissolved in benzene and filtered through a column with silica gel. Concentrating the solution led to the forma-

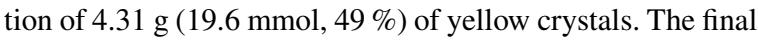
product was crystallized from an ether/hexane mixture.

Cyclization: The crude product of the previous step was placed in a preheated flask with $p$-xylol $\left(130-140{ }^{\circ} \mathrm{C}\right)$ in small portions $(6.0 \mathrm{~g}$ in $250 \mathrm{~mL}$ solvent). The solution was boiled for an $\mathrm{h}$. The solvent was removed under vacuum and the dark residue was cleaned by filtration through silica gel (eluent: $\mathrm{CH}_{2} \mathrm{Cl}_{2}$ ). The product obtained in an almost quantitative yield had a red colour and was pure according to NMR spectroscopy.

Methylation: In a Schlenk tube with $20 \mathrm{~mL}$ of THF the product $(5 \mathrm{~g}, 26 \mathrm{mmol})$ of the cyclization step was dissolved. The solution was cooled $\left(-25\right.$ to $\left.-30{ }^{\circ} \mathrm{C}\right)$ and $\mathrm{KO} t$ $\mathrm{Bu}$ (4.55 g, $40 \mathrm{mmol}$ ) was added. The solution was stirred for $20 \mathrm{~min}$ and then the cooling bath was removed and the mixture was allowed to warm up to r.t. The solution was cooled down again $\left(-25^{\circ} \mathrm{C}\right)$ and $\mathrm{MeI}(7.1 \mathrm{~g}, 50 \mathrm{mmol})$ was added. After 30 min the cooling bath was removed and the mixture allowed to gradually warm to r.t. After a while the magnetic stirrer was able to stir the suspension. After $1 \mathrm{~h}$ 
the mixture was quenched with water. Ether was added and the organic phase was separated. The aqueous phase was extracted twice with $20 \mathrm{~mL}$ of ether. The organic layers were combined and dried with anhydrous $\mathrm{Na}_{2} \mathrm{SO}_{4}$. The solvent was removed. The product had a greenish colour, and the yield was almost quantitative.

Hydrolysis: The solvent was removed under vacuum. The product was dissolved in $\mathrm{H}_{2} \mathrm{O}$, acidified with $\mathrm{HCl}$, extracted with ether and dried over $\mathrm{Na}_{2} \mathrm{SO}_{4}$. Evaporation under vacuum gave a white crystalline solid. After two days the colour turned black (decomposition).

Decarboxylation: The acid product $(1.2 \mathrm{~g}, 6.73 \mathrm{mmol})$ of the previous reaction, quinoline $(8 \mathrm{~mL}, 8.74 \mathrm{mmol})$ and $\mathrm{Cu}$ powder $(0.8 \mathrm{~g}, 12.6 \mathrm{mmol})$ were mixed together in a tube and heated in a preheated bath to $c a .220$ to $230{ }^{\circ} \mathrm{C}$. Gas evolved. The mixture was heated for $30 \mathrm{~min}$ and then allowed to cool down to r.t. The product was purified via column chromatography with silica gel as stationary phase and ether or ether/hexane $(5: 2)$ mixtures as eluants to give $0.42 \mathrm{~g}$ (3.16 mmol, $47 \%$ ) of L2. $-{ }^{1} \mathrm{H} \mathrm{NMR}\left(\mathrm{CDCl}_{3}\right): \delta=3.68$ $\left(\mathrm{s}, \mathrm{N}-\mathrm{CH}_{3}, 6 \mathrm{H}\right), 6.59(\mathrm{~d}, J=2.6 \mathrm{~Hz}, 2 \mathrm{H}, \mathrm{H} 2), 5.95(\mathrm{~d}, J=$ $2.6 \mathrm{~Hz}, 2 \mathrm{H}, \mathrm{H} 3)$.

$N$-Methylthieno[3,2-b]pyrrole (L3): The same general method used to build a condensed pyrrole ring above for $\mathbf{L} 2$ was used to synthesize L3. The overall yield over the five steps was $23 \%$. In accordance with results cited by Aratani and co-workers the condensation step was carried out at $-20{ }^{\circ} \mathrm{C}$ instead of $5-10{ }^{\circ} \mathrm{C}$, improving the yield of this step substantially [26]. $-{ }^{1} \mathrm{H} \mathrm{NMR}\left(\mathrm{CDCl}_{3}\right): \delta=3.80$ (s, $3 \mathrm{H}, \mathrm{N}-\mathrm{CH}_{3}$ ), 7.17 (dd, $\left.J=5.2,1.3 \mathrm{~Hz}, 1 \mathrm{H}, \mathrm{H} 2\right), 7.00$ (dd, $J=5.2,0.8 \mathrm{~Hz}, 2 \mathrm{H}, \mathrm{H} 3), 6.89$ (dd, $J=2.85,0.8 \mathrm{~Hz}, 1 \mathrm{H}, \mathrm{H} 7)$, $6.49(\mathrm{dd}, J=2.85,1.3 \mathrm{~Hz}, 1 \mathrm{H}, \mathrm{H} 6)$.

\section{Tungsten biscarbene complexes}

\section{Synthesis of $\left[(\mathrm{CO})_{5} \mathrm{~W}\left\{\mathrm{C}(\mathrm{OEt}) \mathrm{T}^{\prime} \mathrm{T}^{\prime} \mathrm{C}(\mathrm{OEt})\right\} \mathrm{W}(\mathrm{CO})_{5}\right](\mathbf{1})$}

The synthesis affording dark purple crystals in a yield of $36 \%$ and the characterization of $\mathbf{1}$ have been reported earlier from our laboratories [10]. $-{ }^{1} \mathrm{H}$ NMR $\left(\mathrm{CDCl}_{3}\right): \delta=$ $1.72\left(\mathrm{t}, J=7.1 \mathrm{~Hz}, 6 \mathrm{H}, \mathrm{O}-\mathrm{CH}_{2} \mathrm{CH}_{3}\right), 2.48\left(\mathrm{~s}, 6 \mathrm{H}, \mathrm{CH}_{3}\right)$, 5.04 (q, $J=7.1 \mathrm{~Hz}, 4 \mathrm{H}, \mathrm{O}-\mathrm{CH}_{2} \mathrm{CH}_{3}$ ). - MS (EI): $\mathrm{m} / z$ (based on $\left.{ }^{184} \mathrm{~W}\right)=928\left[\mathrm{M}^{+}\right]$, fragment ions corresponding to the stepwise fragmentation of carbonyl ligands. - IR $\left(\mathrm{CH}_{2} \mathrm{Cl}_{2}\right)$ : $v_{\mathrm{CO}}=2062(\mathrm{~m}), 1983(\mathrm{vw}), 1938(\mathrm{vs}) \mathrm{cm}^{-1}$.

\section{Synthesis of $\left[(\mathrm{CO})_{5} \mathrm{~W}\left\{\mathrm{C}(\mathrm{OEt}) \mathrm{P}^{\prime} \mathrm{P}^{\prime} \mathrm{C}(\mathrm{OEt})\right\} \mathrm{W}(\mathrm{CO})_{5}\right](\mathbf{2})$}

To $\quad N, N^{\prime}$-dimethylpyrrolo[3,2-b]pyrrole $\quad(0.67 \mathrm{~g}, \quad 5.0$ mmol) was added TMEDA (1.5 mL, $10.1 \mathrm{mmol})$ and then, after cooling to $0{ }^{\circ} \mathrm{C}, n$-BuLi $(6.4 \mathrm{~mL}, 10.1 \mathrm{mmol})$. After $10 \mathrm{~min}$ the ice bath was removed and the yellow reaction mixture allowed to warm to $r$. t. The temperature of the reaction mixture was increased to near the boiling point of hexane, and kept for $15 \mathrm{~min}$ at that temperature, after which the mixture was allowed to cool down to r.t.

The mixture was first cooled to $-40{ }^{\circ} \mathrm{C}$ and $\mathrm{W}(\mathrm{CO})_{6}$ ( $3.55 \mathrm{~g}, 10.2 \mathrm{mmol}$ ) was added, where after the solution was allowed to warm up to r.t., until all the $\mathrm{W}(\mathrm{CO})_{6}$ had dissolved. The solution was observed to become dark red-brown in colour. The solvent was removed, a little dichloromethane was added and the solution was again cooled $\left(-30{ }^{\circ} \mathrm{C}\right)$ and $\mathrm{Et}_{3} \mathrm{OBF}_{4}$ (2.0 g, $10.4 \mathrm{mmol}$ - dissolved beforehand in dichloromethane) was added. The solvent was removed after the alkylation was completed. The residue was placed on a silica gel column and the product $\mathbf{2}$ was obtained after eluting with a hexane:dichloromethane $(2: 1)$ mixture and collecting and purifying the dark zone to give $1.02 \mathrm{~g}(0.95 \mathrm{mmol}$, $22.7 \%)$ of $2 .-{ }^{1} \mathrm{H} \mathrm{NMR}\left(\mathrm{CDCl}_{3}\right): \delta=1.69(\mathrm{t}, J=7.1 \mathrm{~Hz}$, $\left.6 \mathrm{H}, \mathrm{O}-\mathrm{CH}_{2} \mathrm{CH}_{3}\right) 3.77$ (s, 6H, N-CH $\mathrm{CH}_{3}, 4.98(\mathrm{q}, J=7.1 \mathrm{~Hz}$, $4 \mathrm{H}, \mathrm{O}-\mathrm{CH}_{2} \mathrm{CH}_{3}$ ), 7.12 (s, 2H, H2). - MS (EI): $\mathrm{m} / z$ (based on $\left.{ }^{184} \mathrm{~W}\right)=898[\mathrm{M}]^{+} .-\mathrm{IR}\left(\mathrm{CH}_{2} \mathrm{Cl}_{2}\right): v_{\mathrm{CO}}=2070(\mathrm{~m}), 1938(\mathrm{~s})$, 1932(vs) $\mathrm{cm}^{-1}$.

\section{Synthesis of $\left[(\mathrm{CO})_{5} \mathrm{~W}\{\mathrm{C}(\mathrm{OEt}) \mathrm{TPC}(\mathrm{OEt})\} \mathrm{W}(\mathrm{CO})_{5}\right](\mathbf{3})$}

First method: To $N$-methylthieno[3,2-b]pyrrole $(0.69 \mathrm{~g}$, $5.0 \mathrm{mmol})$ was added TMEDA $(1.52 \mathrm{~mL}, 10.1 \mathrm{mmol})$ and then, after cooling to $0{ }^{\circ} \mathrm{C}, n$-BuLi $(6.4 \mathrm{~mL}, 10.1 \mathrm{mmol})$. After 10 min the ice bath was removed and the yellow reaction mixture was allowed to warm to r.t. The temperature was increased to near the boiling point of hexane, and kept for $15 \mathrm{~min}$, after which the mixture was allowed to cool down to r.t.

The mixture was first cooled to $-40{ }^{\circ} \mathrm{C}$ and after addition of $\mathrm{W}(\mathrm{CO})_{6}(3.55 \mathrm{~g}, 10.2 \mathrm{mmol})$ stirred for $30 \mathrm{~min}$ and removed from the cold bath. The solution was observed to become dark red-brown in colour. The solvent was removed under reduced pressure and the residue dissolved in $30 \mathrm{~mL}$ of dichloromethane. The solution was again cooled $\left(-30{ }^{\circ} \mathrm{C}\right)$ and then $\mathrm{Et}_{3} \mathrm{OBF}_{4}(2.0 \mathrm{~g}, 10.4 \mathrm{mmol})$, dissolved beforehand in dichloromethane, was added. The solvent was removed after the alkylation was completed. The residue was placed on a silica gel column and the mixture chromatographed by using a hexane:dichloromethane $(5: 1)$ mixture as eluant. The red zone containing the monocarbene complex $\left[\mathrm{W}(\mathrm{CO})_{5}\left\{\mathrm{C}(\mathrm{OEt}) \mathrm{TP}^{\prime} \mathrm{H}\right\}\right]$ was collected but discarded. The biscarbene product 3 was obtained by eluting with a hexane:dichloromethane $(2: 1)$ mixture and collecting the dark zone to give $0.85 \mathrm{~g}(0.95 \mathrm{mmol}, 19 \%)$ of 3 . A third blue band representing $\left[\mathrm{W}(\mathrm{CO})_{4}\left\{\mathrm{C}(\mathrm{OEt}) \mathrm{T}^{\prime} \mathrm{C}(\mathrm{OEt}) \mathrm{P}^{\prime} \mathrm{H}\right\}\right]$ was not collected [27].

Second method: To a cooled $\left(0{ }^{\circ} \mathrm{C}\right)$ solution of $N$-methylthieno[3,2-b]pyrrole $(0.69 \mathrm{~g}, 5.0 \mathrm{mmol})$ dissolved in $40 \mathrm{~mL}$ of THF was added $n$-BuLi $(6.4 \mathrm{~mL}, 10.1 \mathrm{mmol})$ and the reaction mixture stirred for $30 \mathrm{~min}$ and subsequently cooled to $-40{ }^{\circ} \mathrm{C}$ and treated with $\mathrm{W}(\mathrm{CO})_{6}(1.77 \mathrm{~g}, 5.1 \mathrm{mmol})$. After stirring in the cold for $30 \mathrm{~min}$, the cold bath was removed 


\begin{tabular}{|c|c|c|c|}
\hline & 1 & 2 & 3 \\
\hline Formula & $\mathrm{C}_{24} \mathrm{H}_{16} \mathrm{O}_{12} \mathrm{~S}_{2} \mathrm{~W}_{2}$ & $\mathrm{C}_{24} \mathrm{H}_{18} \mathrm{~N}_{2} \mathrm{O}_{12} \mathrm{~W}_{2}$ & $\mathrm{C}_{23} \mathrm{H}_{15} \mathrm{NO}_{12} \mathrm{SW}_{2}$ \\
\hline$M_{\mathrm{r}}$ & 928.19 & 894.10 & 897.12 \\
\hline$T[\mathrm{~K}]$ & $183(2)$ & $183(2)$ & $183(2)$ \\
\hline Cryst. size $\left[\mathrm{mm}^{3}\right]$ & $0.32 \times 0.07 \times 0.07$ & $0.02 \times 0.18 \times 0.10$ & $0.10 \times 0.10 \times 0.08$ \\
\hline Crystal system & triclinic & triclinic & triclinic \\
\hline Space group & $P \overline{1}$ & $P \overline{1}$ & $P \overline{1}$ \\
\hline$a[\AA]$ & $6.4190(3)$ & $6.5306(2)$ & $6.457(5)$ \\
\hline$b[\AA]$ & $8.9568(3)$ & $8.9872(2)$ & $8.619(5)$ \\
\hline$c[\AA]$ & $13.1429(4)$ & $12.6945(4)$ & $13.453(5)$ \\
\hline$\alpha[\mathrm{deg}]$ & $71.728(2)$ & $72.286(1)$ & $71.689(5)$ \\
\hline$\beta[\mathrm{deg}]$ & $81.682(2)$ & $81.923(2)$ & $86.395(5)$ \\
\hline$\gamma[\mathrm{deg}]$ & $81.683(2)$ & $83.705(2)$ & $83.643(5)$ \\
\hline$V\left[\AA^{3}\right]$ & $706.01(5)$ & $700.93(3)$ & $706.1(7)$ \\
\hline$Z$ & 1 & 1 & 1 \\
\hline$D_{\text {calcd }}\left[\mathrm{g} \mathrm{cm}^{-3}\right]$ & 2.183 & 2.118 & 2.110 \\
\hline$\mu\left(\mathrm{MoK}_{\alpha}\right)\left[\mathrm{cm}^{-1}\right]$ & 0.8348 & 0.8263 & 0.8273 \\
\hline$F(000)[\mathrm{e}]$ & 436 & 420 & 420 \\
\hline$h k l$ range & $0 \leq h \leq 8$ & $-8 \leq h \leq 8$ & $-8 \leq h \leq 8$ \\
\hline & $-10 \leq k \leq 11$ & $-11 \leq k \leq 11$ & $-11 \leq k \leq 0$ \\
\hline & $-15 \leq l \leq 16$ & $-15 \leq l \leq 14$ & $-17 \leq l \leq 16$ \\
\hline$\theta$ Range data collection [deg] & $3.23-26.4$ & $3.53-26.35$ & $2.50-27.41$ \\
\hline Reflexions measured & 2870 & 6177 & 3436 \\
\hline Reflexions unique & 2870 & 2833 & 3220 \\
\hline$R_{\text {int }}$ & 0.0480 & 0.0269 & 0.0195 \\
\hline Parameters refined & 181 & 182 & 188 \\
\hline$R(F) / w R(F 2)$ (all reflexions) & $0.0503 / 0.1257$ & $0.0278 / 0.0682$ & $0.0562 / 0.0759$ \\
\hline $\operatorname{GoF}\left(F^{2}\right)$ & 1.083 & 1.051 & 1.044 \\
\hline$\Delta \rho_{\text {fin }}(\max / \min )\left[\mathrm{e}^{-3}\right]$ & $0.986 /-0.396$ & $0.9436 /-0.4471$ & $1.209 /-1.521$ \\
\hline
\end{tabular}

Table 2. Crystal structure data for $1-3$.

and stirring continued for an additional hour. The reaction mixture was again cooled to $-40{ }^{\circ} \mathrm{C}$ and freshly prepared LDA (3.2 $\mathrm{mL}, 5.5 \mathrm{mmol})$ added. After stirring for $30 \mathrm{~min}$, $\mathrm{W}(\mathrm{CO})_{6}(1.77 \mathrm{~g}, 5.1 \mathrm{mmol})$ was added and the reaction mixture removed from the cold and stirred for another h, followed by the alkylation with triethyloxonium tetrafluoroborate $(2.0 \mathrm{~g}, 10.4 \mathrm{mmol})$ as under the first method. After column chromatography $0.94 \mathrm{~g}(1.05 \mathrm{mmol}, 21 \%)$ of $\mathbf{3}$ was isolated.

Third method: The dilithiated ligand $\mathbf{L} \mathbf{3}$ was prepared by the first method and treated with $\mathrm{W}(\mathrm{CO})_{6}(1.77 \mathrm{~g}, 5.1 \mathrm{mmol})$. The solvent was removed in vacuo and the resulting metal acylate washed with several portions of hexane to remove unreacted starting materials. The residue was redissolved in THF and again reacted with $\mathrm{W}(\mathrm{CO})_{6}(1.77 \mathrm{~g}, 5.1 \mathrm{mmol})$. Alkylation was carried out as described for the first method. This methodology improved the yield of the biscarbene complex affording $1.3 \mathrm{~g}(1.2 \mathrm{mmol}, 24 \%)$ of 3. - MS (EI): $\mathrm{m} / \mathrm{z}$ (based on $\left.{ }^{184} \mathrm{~W}\right)=[\mathrm{M}]^{+}$not observed, fragment ions: 813 $\left([\mathrm{M}-3 \mathrm{CO}]^{+}\right), 785,757,729,701,673,645$, etc. representing stepwise fragmentation by loss of carbonyl ligands. ${ }^{1} \mathrm{H} \mathrm{NMR}\left(\mathrm{CDCl}_{3}\right): \delta=1.68\left(\mathrm{t}, J=7.0 \mathrm{~Hz}, 3 \mathrm{H}, \mathrm{O}-\mathrm{CH}_{2} \mathrm{CH}_{3}\right)$, $1.71\left(\mathrm{t}, J=7.0 \mathrm{~Hz}, 3 \mathrm{H}, \mathrm{O}-\mathrm{CH}_{2} \mathrm{CH}_{3}\right) 3.88\left(\mathrm{~s}, 3 \mathrm{H}, \mathrm{N}-\mathrm{CH}_{3}\right)$, 4.97 (q, $\left.J=7.0 \mathrm{~Hz}, 2 \mathrm{H}, \mathrm{O}-\mathrm{CH}_{2} \mathrm{CH}_{3}\right), 5.01$ (q, $J=7.0 \mathrm{~Hz}, 2 \mathrm{H}$, O- $\mathrm{CH}_{2} \mathrm{CH}_{3}$ ), 7.59 (s, 1H, H6), 7.89 (s, 1H, H3). - IR (hexane): $v_{\mathrm{CO}}=2061(\mathrm{~m}), 1979(\mathrm{vw}), 1943(\mathrm{~s}), 1935(\mathrm{vs}) \mathrm{cm}^{-1}$.

\section{$X$-Ray structure determination}

The intensity data were collected at $-90{ }^{\circ} \mathrm{C}$ on a Nonius Kappa CCD diffractometer for compounds $\mathbf{1}$ and $\mathbf{2}$ and on a NONIUS CAD4 diffractometer for compound $\mathbf{3}$, using graphite-monochromated $\mathrm{Mo} K_{\alpha}$ radiation. Data were corrected for Lorentz and polarization effects and for absorption [28-31]. The structures were solved by Direct Methods (SHELXS) [32] and refined by full-matrix least-squares techniques against $F_{\mathrm{O}}{ }^{2}$ (SHELXL-97) [33]. The hydrogen atoms of the structures were included at calculated positions with fixed thermal parameters. All non-hydrogen atoms were refined anisotropically. XP (SIEMENS Analytical X-ray Instruments, Inc.) was used for structure representations. The structure of $\mathbf{3}$ is disordered around the inversion centre. Other experimental details are given in Table 2.

CCDC 634278 (1), 634279 (2) and 634280 (3) contain the supplementary crystallographic data for this paper. These data can be obtained free of charge from The Cambridge Crystallographic Data Centre via www.ccdc.cam.ac.uk/ data_request/cif.

\section{Acknowledgement}

This work was supported financially by the University of Pretoria and by the National Research Foundation of South Africa under Grant No's: 2047221(SL). 
[1] a) T. B. Rauchfuss, Prog. Inorg. Chem. 1991, 39, 259; b) R. J. Angelici, Coord. Chem. Rev. 1990, 105, 61; c) S. Lotz, P.H. van Rooyen, R. Meyer, $A d v$. Organomet. Chem. 1995, 37, 219.

[2] a) G.C. Fu, Acc. Chem. Res. 2006, 39, 853; b) K. Öfele, E. Dotzauer, J. Organomet. Chem. 1971, 30, 211; c) M. J. Zaworotko, R. J. Stamps. M. T. Ledet, H. Zhang, J.L. Atwood, Organometallics 1985, 4, 1697.

[3] a) F. Garcia, C. Gálvez, Synthesis 1985, 143; b) E. Campaige, J. Ashby, S. W. Osborn, J. Heterocycl. Chem. 1969, 6, 885.

[4] a) O. Kobayashi, Phosphorus and Sulfur 1989, 43, 187; b) S. Musmanni, J.P. Ferraris, J. Chem. Soc., Chem. Commun. 1993, 172; c) M. Hmyene, A. Yassar, M. Escorne, A. Percheron-Guegan, F. Garnier, Adv. Mater. 1994, 6, 564.

[5] a) J. M. Tour, Chem. Rev. 1996, 96, 37; b) R. Lazzaroni, J. Riga, J. J. Verbist, L. Christiaens, M. Renson, J. Chem. Soc., Chem. Commun. 1985, 999; c) D. Lorey, K. D. Robinson, Y. Okuda, J. L.Atwood, M. P. Cava, J. Chem. Soc., Chem. Commun. 1993, 345.

[6] S. Le Stang, F. Paul, C. Lapinte, Organometallics 2000 , 19, 1035.

[7] R. Chindulla, C. Najera, M. Yus, Chem. Rev. 2004, 104, 2667.

[8] J. Barluenga, M. Tomás, E. Rubio, J. A. LópezPelegrin, S. Garcia-Granda, M. P. Priede, J. Am. Chem. Soc. 1999, 121, 3065.

[9] C. Crause, H. Görls, S. Lotz, J. Chem. Soc., Dalton Trans. 2005, 1649.

[10] M. Landman, H. Görls, S. Lotz, Eur. J. Inorg. Chem. 2001, 233.

[11] M. Landman, H. Görls, S. Lotz, Z. Anorg. Allg. Chem. 2002, 628, 2037.

[12] R. Lazzaroni, J. P. Boutique, J. Riga, J. J. Verbist, J. Chem. Soc., Perkin. Trans. II, 1985, 97.

[13] a) Y. M. Terblans, S. Lotz, J. Chem. Soc., Dalton Trans. 1997, 2177; b) Y. M. Terblans, H. M. Roos, S. Lotz, J. Organomet. Chem. 1998, 566, 133; c) M. Landman, H. Görls, S. Lotz, J. Organomet. Chem. 2001, 617$618,280$.
[14] K. S. Choi, K. Sawada, H. Dong, M. Hoshino, J. Nakayama, Heterocycles 1994, 38, 143.

[15] J. Teste, N. Lozac'h, Bull. Soc. Chim. Fr. 1995, 422

[16] H. Hemetsberger, D. Knittel, Monatshefte für Chemie 1972, 103, 194.

[17] J. M. Mallan, R. L. Bebb, Chem. Rev. 1969, 69, 693.

[18] M. Landman, H. Görls, S. Lotz, J. Organomet. Chem. 2001, 617-618, 282.

[19] L. Brandsma, H. Verkruijsse, Preparative Organometallic Chemistry, Springer, Berlin, 1987.

[20] A. Aoki, T. Fujimura, E. Nakamura, J. Am. Chem. Soc. 1992, 114, 2985.

[21] D. Liles, S. Lotz, Acta Crystallogr. 2006, E62, m331.

[22] R. J. Goddard, R. Hoffmann, E. D. Jemmis, J. Am. Chem. Soc. 1980, 102, 7667.

[23] G. H. Spies, R. J. Angelici, Organometallics 1987, 6, 1897.

[24] H. Meerwein, Org. Synth. 1966, 46, 113

[25] a) T. Wieland, R. Müller, E. Niemann, L. Birkofer, A. Schöberl, A. Wagner, H. Söll, Methoden der Organischen Chemie (Houben Weyl), Vol. XI/2, 1958, p. 353; b) C. Grundmann, Methoden der Organischen Chemie (Houben Weyl), Vol. X/3, 1965, p. 796.

[26] T. Aratani, H. Yoshihara, G. Suzukamo, Tetrahedron Lett. 1989, 30, 1655.

[27] C. Crause, unpublished results.

[28] MOLEN, An Interactive Structure Solution Procedure, Enraf-Nonius, Delft (The Netherlands) 1990.

[29] COLLECT, Data Collection Software, Nonius B. V. (The Netherlands) 1998.

[30] Z. Otwinowski, W. Minor, Processing of X-Ray Diffraction Data Collected in Oscillation Mode in Methods in Enzymology, Vol. 276, Macromolecular Crystallography, Part A, (Eds.: C. W. Carter Jr., R. M. Sweet, Academic Press, New York 1997, pp. 307 - 326.

[31] R.H. Blessing, S. ORTAV, Acta Crystallogr. 1995, A51, 33-38.

[32] G. M. Sheldrick, Acta Crystallogr. 1990, A46, 467.

[33] G. M. Sheldrick, SHELXL-97 (Release 97-2). University of Göttingen, Göttingen (Germany) 1997. 